\title{
Effect of Switching From an Anti-Diabetic Loose Dose Combination to a Fixed Dose Combination Regimen at Equivalent Dosage for 6 Months on Glycemic Control in Japanese Patients With Type 2 Diabetes: A Pilot Study
}

\author{
Kazutaka Aoki a, b, j, Mieko Nagakurac ${ }^{\mathrm{c}}$, Masataka Tagurid ${ }^{\mathrm{d}}$, Hiroshi Kamiyama ${ }^{\mathrm{b}}$, Makoto Masumura ${ }^{\mathrm{e}}$, \\ Tadashi Furuie ${ }^{\mathrm{f}}$, Masanao $\mathrm{Oka}^{\mathrm{g}}$, Kazunari Kamiko ${ }^{\mathrm{b}}$, Shigeru Nakajima ${ }^{\mathrm{h}}$, \\ Noriko Akemai, Yasuo Terauchi ${ }^{b, j}$
}

\begin{abstract}
Background: Patients with type 2 diabetes mellitus often take multiple anti-diabetic drugs for a long period. Fixed dose combination (FDC) therapy is expected to improve drug adherence for patients with diabetes. The effect of switching from a loose dose combination (LDC) regimen to an FDC regimen at equivalent dosage on glycemic control has not been evaluated fully. Therefore, we investigated the effect of switching from LDC to FDC at equivalent dosage for 6 months on glycemic control in Japanese patients with type 2 diabetes.

Methods: Thirty-eight Japanese patients with type 2 diabetes who were taking anti-diabetic drugs including pioglitazone + metformin, pioglitazone + alogliptin, or pioglitazone + glimepiride were enrolled. These drugs were switched to an FDC of Metact $^{\circledR}$, Liobel ${ }^{\circledR}$ or Sonias ${ }^{\circledR}$, respectively, at equivalent dosage. Other anti-diabetic drugs and units of insulin were not changed during the study if possible. HbAlc and body weight were measured 0, 2, 4 and 6 months after switching from an LDC to FDC. We also conducted a questionnaire survey 2 months after the start of the FDC regimen.
\end{abstract}

Manuscript submitted May 3, 2017, accepted May 24, 2017

aDepartment of Internal Medicine, Kanagawa Dental University, Yokosuka, Japan

${ }^{b}$ Department of Endocrinology and Metabolism, Yokohama City University Graduate School of Medicine, Yokohama, Japan

'Nagakura Clinic, Yokohama, Japan

${ }^{\mathrm{d}}$ Department of Biostatistics and Epidemiology, Yokohama City University

Graduate School of Medicine, Yokohama, Japan

'Masumura Naika Clinic, Yokohama, Japan

fFuruie Naika Clinic, Yokohama, Japan

gOka Naika Clinic, Yokohama, Japan

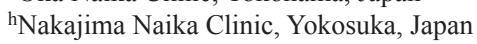

iIHI Yokohama Clinic, Yokohama, Japan

jCorresponding Author: Kazutaka Aoki, Department of Internal Medicine, Kanagawa Dental University, 82 Inaoka, Yokosuka 238-8580, Japan. Email: k.aoki@kdu.ac.jp; Yasuo Terauchi, Department of Endocrinology and Metabolism, Yokohama City University Graduate School of Medicine, 3-9 Fuku-ura, Kanazawa-ku, Yokohama 236-0004, Japan.

Email: terauchi@yokohama-cu.ac.jp

doi: https://doi.org/10.14740/jocmr3067w
Results: HbA1c levels at 2, 4, and 6 months were not significantly changed compared with prior to switching from an LDC to FDC regimen. Moreover, $74.2 \%$ of patients considered decreasing the number of drugs to be "very good" or "good".

Conclusion: HbAlc levels did not differ between patients receiving LDC and FDC therapy at equivalent dosage in this study.

Keywords: Fixed dose combination; Loose dose combination; Type 2 diabetes

\section{Introduction}

Patients with type 2 diabetes often take multiple anti-diabetic drugs for a long period. As they often have comorbidities such as hypertension and hyperlipidemia, they may take other drugs daily as well. Medication non-adherence is prevalent among patients with diabetes mellitus and is associated with adverse clinical outcomes such as increased risks for all-cause hospitalization and all-cause mortality [1]. Therefore, the maintenance of good long-term adherence is important for the treatment of diabetes. Good adherence may be difficult to obtain, particularly among patients with busy social lives.

Recently, we investigated how to improve the drug adherence of patients with type 2 diabetes who are taking alpha glucosidase inhibitors, glinides, and dipeptidyl peptidase-4 (DPP4 ) inhibitors [2-4]. Fixed dose combination (FDC) therapy or a weekly DPP-4 inhibitor is expected to improve drug adherence for patients with diabetes $[5,6]$. Many FDC regimens for hypertension are available in Japan, but only five for diabetes. In retrospective studies, switching from loose dose combination (LDC) therapy to FDC therapy improved adherence [7, 8]. In another retrospective study, the most recent $\mathrm{HbAlc}$ level of patients who took an FDC of DPP-4 inhibitor and metformin was lower than that of patients who took an LDC of DPP-4 inhibitor and metformin free form [9]. Glycemic control may be improved by increased drug adherence due to the administration of FDC therapy. However, the effect of switching from an LDC to an FDC at equivalent dosage on glycemic control has 


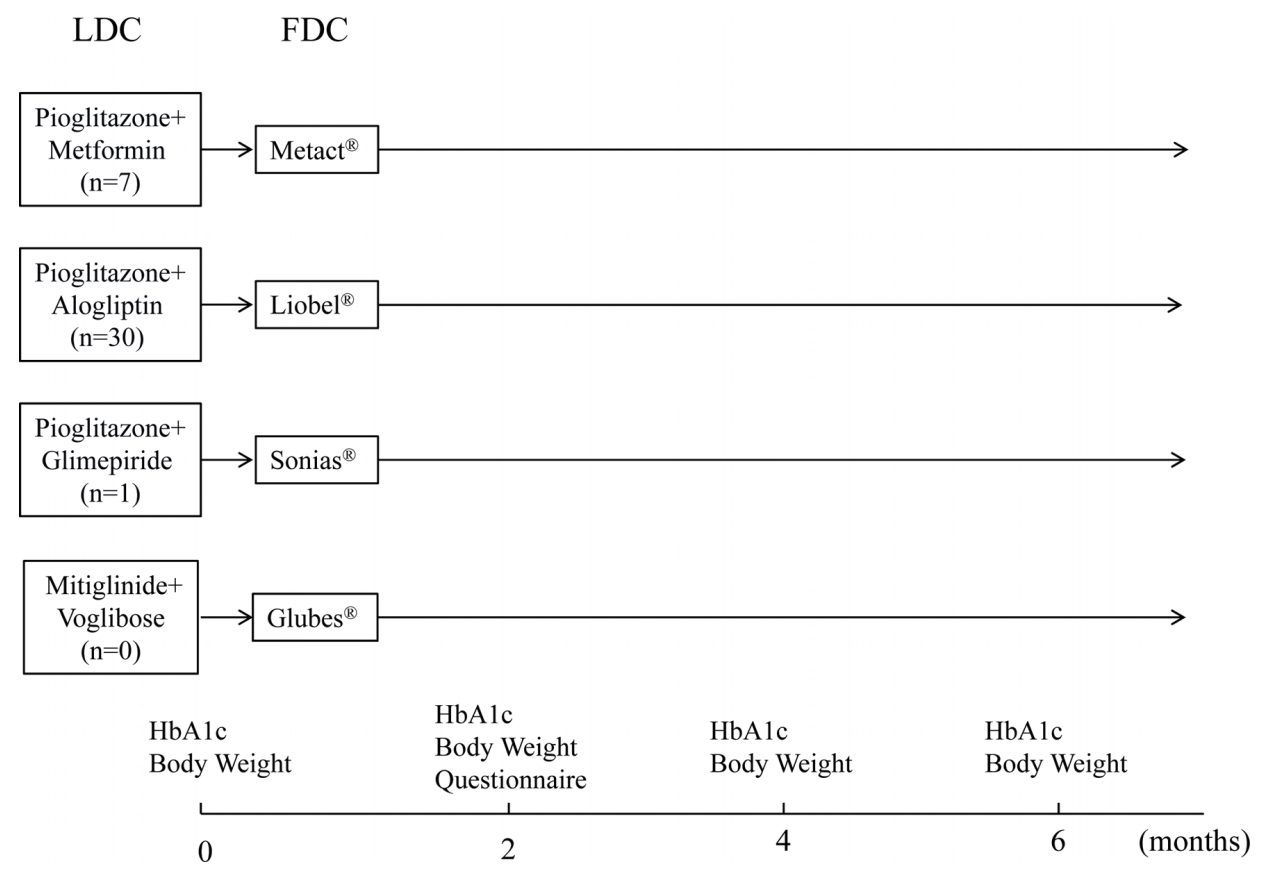

Figure 1. Study design. Thirty-eight Japanese patients with type 2 diabetes who were taking anti-diabetic drugs including LDC such as pioglitazone + metformin, pioglitazone + alogliptin, or pioglitazone + glimepiride were enrolled. These drugs were switched to an FDC of Metact ${ }^{\circledR}$, Liobel ${ }^{\circledR}$ or Sonias ${ }^{\circledR}$, respectively, at equivalent dosage. No patients in the study took mitiglinide + voglibose, which can be switched to Glubes ${ }^{\circledR}$. HbA1c and body weight were measured 0, 2, 4 and 6 months after switching from an LDC to FDC. We also conducted a questionnaire survey 2 months after the start of the FDC regimen.

not been evaluated fully. Therefore, we investigated the effect of switching from an LDC to an FDC at equivalent dosage for 6 months on glycemic control in Japanese patients with type 2 diabetes.

\section{Materials and Methods}

This study was a prospective observational study to investigate the clinical effects of FDC therapy in patients with type 2 diabetes. After obtaining approval from the Institutional Ethics Review Committee of Yokohama City University, the objective of the study was explained to all subjects, and written informed consent was obtained prior to the start of the study. A total of 38 patients were recruited during the study registration period (from February 2013 to March 2016) and their data were analyzed in a pilot study (Figure 1).

Japanese patients with type 2 diabetes who were taking anti-diabetic drugs including pioglitazone + metformin, pioglitazone + alogliptin, pioglitazone + glimepiride, or mitiglinide + voglibose were enrolled between February 2013 and March 2016. The hospital or clinics that participated this study were Yokohama City University Hospital, Nagakura Clinic, Nakajima Naika Clinic, Oka Naika Clinic, Furuie Naika Clinic, IHI Yokohama Clinic, and Masumura Naika Clinic. Herein, a regimen comprising $15 \mathrm{mg}$ of pioglitazone and $500 \mathrm{mg}$ of metformin was switched to Metact ${ }^{\circledR}$ LD (FDC at equivalent doses of pioglitazone and metformin). Similarly, $30 \mathrm{mg}$ of pioglitazone and $500 \mathrm{mg}$ of metformin were switched with Metact ${ }^{\mathrm{R}}$ $\mathrm{HD}$ (FDC at equivalent doses of pioglitazone and metformin),
$15 \mathrm{mg}$ of pioglitazone and $25 \mathrm{mg}$ of alogliptin were switched with Liobel ${ }^{\circledR} \mathrm{LD}$ (FDC at equivalent doses of pioglitazone and alogliptin), $30 \mathrm{mg}$ of pioglitazone and $25 \mathrm{mg}$ of alogliptin were switched with Liobel ${ }^{\circledR} \mathrm{HD}$ (FDC at equivalent doses of pioglitazone and alogliptin), $15 \mathrm{mg}$ of pioglitazone and $1 \mathrm{mg}$ of glimepiride were switched with Sonias ${ }^{\circledR}$ LD (FDC at equivalent doses of pioglitazone and glimepiride), $30 \mathrm{mg}$ of pioglitazone and $1 \mathrm{mg}$ of glimepiride were switched with Sonias ${ }^{\mathbb{R}}$ HD (FDC at equivalent doses of pioglitazone and glimepiride) and $10 \mathrm{mg}$ of mitiglinide and $0.2 \mathrm{mg}$ of voglibose were switched with Glubes ${ }^{\circledR}$ (FDC at equivalent doses of mitiglinide and voglibose). Other anti-diabetic drugs and units of insulin were not changed through the study if possible.

The HbAlc level and body weight were measured $0,2,4$ and 6 months after switching from an LDC to FDC. We also conducted a questionnaire survey 2 months after the start of FDC. Question 1: How do you feel about the decrease in the number of drugs? Question 2: Has the number of medicine doses you have forgotten decreased? Question 3: How much of a benefit have you experienced in decreasing drug costs? Question 4: Do you feel there has been a change in your glycemic control? Question 5: Which do you prefer to take: FDC or LDC?

Data are expressed as the mean \pm standard error. SAS software (SAS Institute Inc., Cary, NC, USA) was used for the statistical analysis. The HbAlc levels and body mass index (BMI) of patients were analyzed using a mixed model; we compared each value at 2, 4, and 6 months with that at 0 months and differences with $P$ values less than 0.05 were considered significant. 

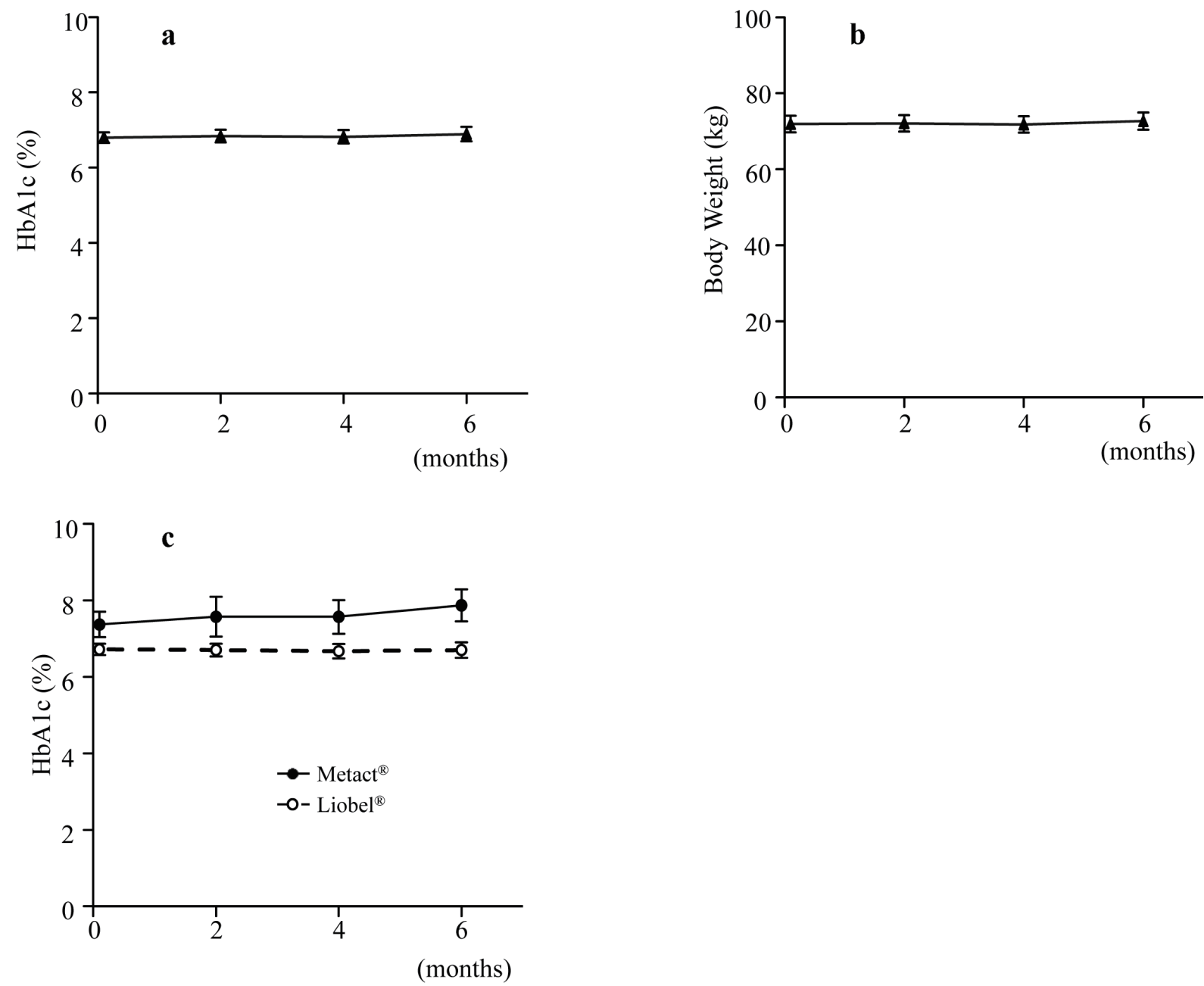

Figure 2. Changes in $\mathrm{HbA} 1 \mathrm{c}$ and body weight after switching from an LDC to FDC. (a) HbA1c levels of all patients. (b) Body weight of all patients. (c) HbA1c levels of patients taking Metact $^{\circledR}$ (FDC of pioglitazone and metformin, $\left.n=7\right)$ or Liobel ${ }^{\circledR}($ FDC of pioglitazone and alogliptin, $n=30$ ).

\section{Results}

\section{Baseline characteristics}

A total of 38 patients (29 male and nine female) with a mean age of $63.0 \pm 1.5$ years and a mean body mass index $(\mathrm{BMI})$ of $26.7 \pm 2.7 \mathrm{~kg} / \mathrm{m}^{2}$ were enrolled. The mean HbA1c level was $6.8 \pm 0.1 \%$, and the average duration of diabetes was $8.3 \pm 0.8$ years.

The number of types of all drugs taken was $5.3 \pm 0.3$, and the number of all drugs taken was $8.1 \pm 0.8$. The number of types of anti-diabetic drugs taken was $2.9 \pm 0.1$, and the number of anti-diabetic drugs taken was $4.6 \pm 0.8$.

\section{Changes in HbA1c level and body weight}

In this study, five patients took $15 \mathrm{mg}$ of pioglitazone and $500 \mathrm{mg}$ of metformin, which were switched to Metact $^{\circledR}$ LD, and two patients took $30 \mathrm{mg}$ of pioglitazone and $500 \mathrm{mg}$ of metformin, which were switched to Metact ${ }^{\circledR}$ HD. Nineteen patients took $15 \mathrm{mg}$ of pioglitazone and $25 \mathrm{mg}$ of alogliptin, which were switched to Liovel ${ }^{\circledR} \mathrm{LD}$, and 11 patients took $30 \mathrm{mg}$ of pioglitazone and $25 \mathrm{mg}$ of alogliptin, which were switched to Liovel ${ }^{\circledR} \mathrm{HD}$. One patient took $15 \mathrm{mg}$ of pioglitazone and $1 \mathrm{mg}$ of glimepiride, which were switched to Sonias ${ }^{\circledR}$ LD. No patients in the study took mitiglinide and voglibose, which can be switched to Glubes ${ }^{\circledR}$. Five patients dropped out of the study. Two patients did not visit the hospital or clinic at 2 or 6 months, respectively. One patient had another antidiabetic drug added to the regimen. One patient stopped taking Sonias ${ }^{\circledR}$ LD due to edema. One patient stopped taking Metact ${ }^{\circledR}$ HD because of the increasing drug cost (generics for pioglitazone and metformin are available in Japan).

As shown in Figure 2a and b, HbAlc levels and body weight were not significantly different at 2, 4, and 6 months compared to that at 0 months. As shown Figure $2 \mathrm{c}, \mathrm{HbAlc}$ levels did not differ at 2, 4, and 6 months compared to that at 0 months in the Metact $^{\circledR}(n=7)$ group or Liobel ${ }^{\circledR}$ group (n 

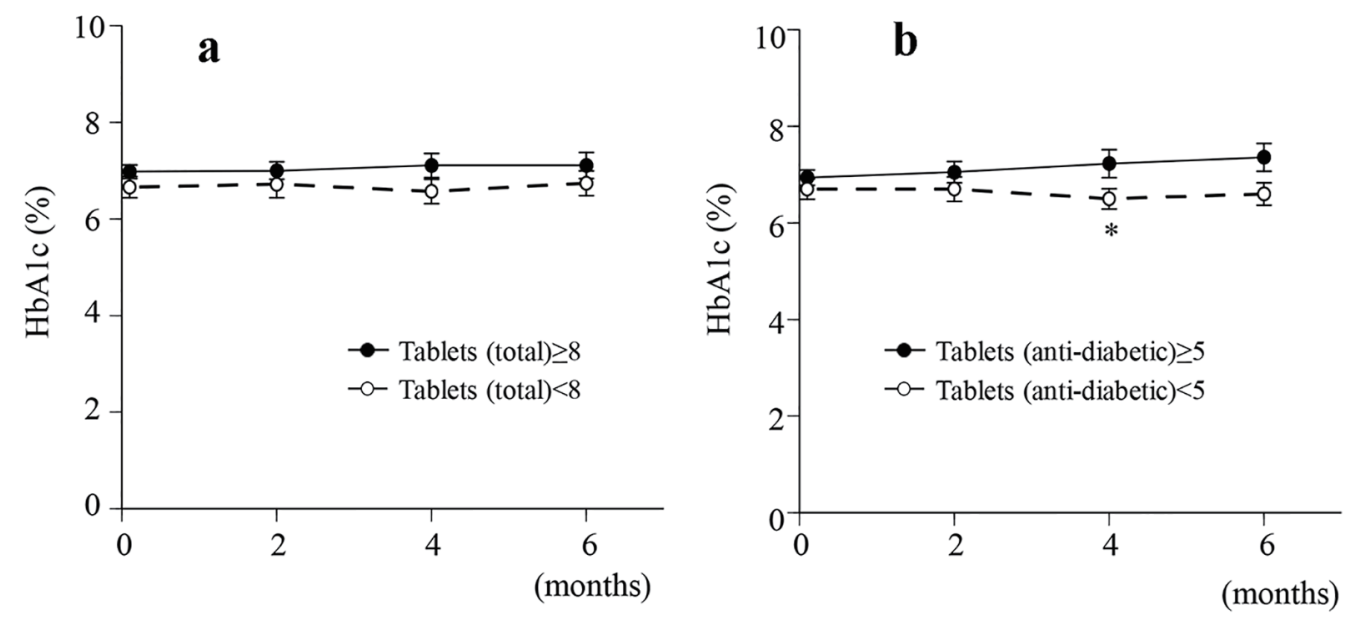

Figure 3. Changes in $\mathrm{HbA} 1 \mathrm{c}$ after switching from an LDC to FDC. (a) HbA1c levels of patients taking more than eight tablets ( $\mathrm{n}$ $=17)$ or less than eight tablets $(n=21)$ in total. (b) HbA1c levels of patients taking more than five anti-diabetic tablets $(n=16)$ or less than five anti-diabetic tablets $(n=22) .{ }^{*} P<0.05$ vs. 0 months in each group.

=30). As shown in Figure 3a, HbA1c levels were not different at 2, 4, and 6 months compared to that at 0 months in the group taking more than eight tablets in total $(\mathrm{n}=17)$ and the group taking less than eight tablets in total $(\mathrm{n}=21)$. As shown in Figure 3b, HbA1c levels were not different at 2, 4, and 6 months compared to that at 0 months in the group taking more than five anti-diabetic tablets $(\mathrm{n}=16)$. In the group taking less than five anti-diabetic tablets $(n=22)$, the HbA1c levels were significantly decreased at 4 months compared to that at 0 months; however, the HbAlc levels were not different at 2 and 6 months compared to that at 0 months (Fig. $3 b$ ).

\section{Questionnaire}

With respect to question 1, 74.2\% of subjects responded "very good" or "good" (Table 1). With respect to question 2, 54.8\% selected "decreased" or "decreased a little", but $45.2 \%$ of patients selected "not changed". With respect to question 3, $38.7 \%$ of patients saw significant or modest benefits; however, $61.3 \%$ of patients saw "almost no benefit" or "no benefit or unchanged". With respect to question $4,42 \%$ of patients answered "improved" or "improved slightly", but 54.8\% of patients answered "not changed". With respect to question 5, $54.8 \%$ of patients preferred to receive an FDC, and $41.9 \%$ of patients answered "either".

\section{Discussion}

The most important finding in our study was the fact that the HbA1c level did not significantly differ after switching from an LDC to FDC at equivalent dosage.

In Japan, FDC for anti-diabetic drugs comprise combinations of pioglitazone + metformin, pioglitazone + glimepiride, pioglitazone + alogliptin, and voglibose + mitiglinide; recently, metformin + vildagliptin has become available as well. The benefits of an FDC are 1) a decrease in the number of drugs, 2 ) decreased drug costs in most cases, and 3) an improvement in drug adherence due to 1) and 2). In fact, an FDC regimen was shown to improve medication adherence in a meta-analysis [10]. A $10 \%$ increase in adherence to anti-diabetic drugs is associated with a $0.1 \%$ decrease in HbAlc level [11]. In a retrospective study, patients with type 2 diabetes treated with FDC had a low rate of non-persistence [7]. Drug adherence was reported to increase when patients were switched from LDC therapy with pioglitazone and metformin to analogous FDC therapy [8]. It was reported that treatment with FDC was associated with lower costs and increased possibility of achieving the target $\mathrm{HbAlc}$ in a retrospective study [12]. Indeed, the HbA1c level of patients who took an FDC of DPP-4 inhibitor and metformin was lower than that of patients who took an LDC of DPP-4 inhibitor and metformin free form in the retrospective study [9]. However, whether switching from an anti-diabetic LDC to FDC regimen at equivalent dosages in patients with type 2 diabetes improves glycemic control remains poorly understood. We evaluated this prospective observational pilot study and $\mathrm{HbA} 1 \mathrm{c}$ levels did not significantly differ after switching from an LDC to FDC at equivalent dosage. HbA1c levels were not different at 2, 4, and 6 months compared to that at 0 months in both the group taking more than eight tablets and the group taking less than eight tablets in total. HbA1c levels were not different at 2, 4, 6 months compared to that at 0 months in the group taking more than five anti-diabetic tablets. In the group taking less than five antidiabetic tablets, HbA1c levels were significantly decreased at 4 months compared to that at 0 months; however, HbAlc levels were not different at 2 and 6 months compared to that at 0 months. When the number of anti-diabetic drugs taken is low, switching from an LDC to FDC regimen may be effective; however, this effect is limited.

As the mean number of all drugs taken was $8.1 \pm 0.8$, the effect of switching from an LDC to FDC regimen on drug adherence and glycemic control by decreasing the number of 
Table 1. Questionnaire Survey

Q1: How do you feel about the decrease in the number of drugs?

$\begin{array}{llllll}\text { Answer } & \text { Very good } & \text { Good } & \text { Not changed } & \text { Not good } & \text { Bad } \\ \mathrm{n}(\%) & 7(22.6) & 16(51.6) & 8(25.8) & 0(0.0) & 0(0.0)\end{array}$

Q2: Has the number of medicine doses you have forgotten decreased?

$\begin{array}{llllll}\text { Answer } & \text { Decreased } & \text { Decreased a little } & \text { Not changed } & \text { Increased a little } & \text { Increased } \\ \mathrm{n}(\%) & 13(41.9) & 4(12.9) & 14(45.2) & 0(0.0) & 0(0.0)\end{array}$

Q3: How much of a benefit have you experienced in decreasing drug costs?

$\begin{array}{lllll}\text { Answer } & \text { Significant benefit } & \text { Modest benefit } & \text { Almost no benefit } & \text { No benefit or unchanged } \\ \mathrm{n}(\%) & 1(3.2) & 11(35.5) & 7(22.6) & 12(38.7)\end{array}$

Q4: Do you feel there has been a change in your glycemic control?

$\begin{array}{llllll}\text { Answer } & \text { Improved } & \text { Improved slightly } & \text { Not changed } & \text { Worsen slightly } & \text { Worsen } \\ \mathrm{n}(\%) & 6(19.4) & 7(22.6) & 17(54.8) & 1(3.2) & 0(0.0)\end{array}$

Q5: Which do you prefer to take: FDC or LDC?

\begin{tabular}{llll} 
Answer & LDC & FDC & Either \\
$\mathrm{n}(\%)$ & $1(3.2)$ & $17(54.8)$ & $13(41.9)$ \\
\hline
\end{tabular}

drugs might be small. On the questionnaire, many patients indicated that decreasing the number of drugs is preferable; however, the effects of switching from an LDC to FDC regimen on the number of forgotten doses of medicine and on costs are limited. Therefore, $41.9 \%$ of patients said either FDC or LDC would be best. We would like to evaluate this switching effect in patients who are taking two or three anti-diabetic drugs.

The present study had several limitations. As the number of subjects in this study was small and the term of the study was short, larger-scale and longer-term studies are needed in the future. We also would like to evaluate adherence after switching from an LDC to FDC in a further study.

In conclusion, many patients felt positively about decreasing the number of drugs they took, and $\mathrm{HbAlc}$ levels did not differ after switching from an LDC to FDC at an equivalent dosage in this study.

\section{Acknowledgments}

This work was supported in part by Grants-in-Aid for Scientific Research (C) 16K09806, (B) 21390282, and (B) 24390235 from the Ministry of Education, Culture, Sports, Science and Technology (MEXT) of Japan, and a Medical Award from the Japan Medical Association.

\section{Conflicts of Interest}

Yasuo Terauchi received honoraria for lectures from MSD; Ono Pharmaceutical Co. Ltd; Boehringer Ingelheim GmbH; Takeda Pharmaceutical Company Ltd; Tanabe-Mitsubishi Pharma; Daiichi-Sankyo Company Ltd; Sanwa Kagaku Kenkyusho Co., Ltd; Novo Nordisk Pharma Ltd; Eli Lilly and Company; Sanofi; DaiNippon-Sumitomo; Shionogi \& Co., Ltd; Bayer Yakuhin Ltd; Astellas Pharma Inc.; and Astra Zeneca and ob- tained research support from MSD; Ono Pharmaceutical Co. Ltd; Boehringer Ingelheim GmbH; Takeda Pharmaceutical Company Ltd; Tanabe-Mitsubishi Pharma; Daiichi-Sankyo Company Ltd; Sanwa Kagaku Kenkyusho Co., Ltd; Novo Nordisk Pharma Ltd; Eli Lilly and Company; Sanofi; Astellas Pharma Inc.; and Astra Zeneca. Kazutaka Aoki obtained research support from Sanwa Kagaku Kenkyusho Co., Ltd.

\section{References}

1. Ho PM, Rumsfeld JS, Masoudi FA, McClure DL, Plomondon ME, Steiner JF, Magid DJ. Effect of medication nonadherence on hospitalization and mortality among patients with diabetes mellitus. Arch Intern Med. 2006;166(17):1836-1841.

2. Aoki K, Nakajima S, Nezu U, Shinoda K, Terauchi Y. Comparison of pre- vs. postmeal administration of miglitol for 3 months in type 2 diabetic patients. Diabetes Obes Metab. 2008;10(10):970-972.

3. Kamiyama H, Aoki K, Nakajima S, Shinoda K, Kamiko K, Taguri M, Terauchi Y. Effect of Switching from Sulphonylurea to Repaglinide Twice or Three Times Daily for 4 Months on Glycemic Control in Japanese Patients with Type 2 Diabetes. Intern Med. 2016;55(13):1697-1703.

4. Kamiko K, Aoki K, Kamiyama H, Taguri M, Shibata E, Ashiya Y, Minagawa F, et al. Comparison of the administration of teneligliptin every day versus every other day in Japanese patients with type 2 diabetes: a randomized non-inferior test. J Clin Pharmacol. 2015;55(2):144-151.

5. Hutchins V, Zhang B, Fleurence RL, Krishnarajah G, Graham J. A systematic review of adherence, treatment satisfaction and costs, in fixed-dose combination regimens in type 2 diabetes. Curr Med Res Opin. 2011;27(6):11571168 .

6. Kaku K. First novel once-weekly DPP-4 inhibitor, trela- 
gliptin, for the treatment of type 2 diabetes mellitus. Expert Opin Pharmacother. 2015;16(16):2539-2547.

7. Barner JC. Adherence to oral antidiabetic agents with pioglitazone and metformin: comparison of fixed-dose combination therapy with monotherapy and loose-dose combination therapy. Clin Ther. 2011;33(9):1281-1288.

8. Lokhandwala T, Smith N, Sternhufvud C, Sorstadius E, Lee WC, Mukherjee J. A retrospective study of persistence, adherence, and health economic outcomes of fixeddose combination vs. loose-dose combination of oral anti-diabetes drugs. J Med Econ. 2016;19(3):203-212.

9. Benford M, Milligan G, Pike J, Anderson P, Piercy J, Fermer S. Fixed-dose combination antidiabetic therapy: realworld factors associated with prescribing choices and re- lationship with patient satisfaction and compliance. Adv Ther. 2012;29(1):26-40.

10. Bangalore S, Kamalakkannan G, Parkar S, Messerli FH. Fixed-dose combinations improve medication compliance: a meta-analysis. Am J Med. 2007;120(8):713-719.

11. Rozenfeld Y, Hunt JS, Plauschinat C, Wong KS. Oral antidiabetic medication adherence and glycemic control in managed care. Am J Manag Care. 2008;14(2):71-75.

12. Williams SA, Buysman EK, Hulbert EM, Bergeson JG, Zhang B, Graham J. Hemoglobin A1c outcomes and health care resource use in type 2 diabetes mellitus patients treated with combination oral antidiabetic drugs through step therapy and loose-dose and fixed-dose combinations. Manag Care. 2012;21(7):40-48. 